\title{
AVALIAÇÃO DA PRECIPITAÇÃO DA MICRORREGIÃO DO SERIDÓ ORIENTAL PARAIBANO
}

\author{
André Luiz da SILVA ${ }^{1}$ \\ Gyovane Santos da SILVA² \\ Walkimer Santana da SILVA3 \\ Lincoln Eloi de ARAÚJO4
}

\begin{abstract}
Resumo
O Nordeste brasileiro caracteriza-se por ter grandes irregularidades na precipitação, que é uma das variáveis climáticas mais importantes. Por isso devemos conhecê-la, não só para caracterizar o clima do continente, mas também para planejar inúmeras atividades produtivas, tais como agricultura, pecuária, geração de energia hidrelétrica, dentre outras. Diante disso o trabalho se compromete a avaliar a variabilidade da precipitação do Seridó Oriental Paraibano, através da análise espaço-temporal mensal e anual da precipitação e identificar os ciclos secos e chuvosos da área estudada com o auxílio do Índice de Anomalia de Chuva (IAC). Para isso, os dados pluviométricos utilizados na pesquisa correspondem as séries mensais de precipitação pluviométrica no período de 1994 a 2014 fornecidos pela AESA para a avaliação espaço-temporal da precipitação e para o cálculo do Îndice de Anomalia de Chuva (IAC). Os dois anos extremamente secos foram 1998 e 2012 e os dois anos extremamente úmidos foram 2009 e 2011. A área apresenta dois períodos distintos, um período úmido, que vai de janeiro a junho e um período seco, de julho a dezembro. Constataram-se precipitações mais concentradas nas partes Noroeste e sudoeste, sendo em maior abundancia na região sudoeste.
\end{abstract}

Palavras-chave: Índice de Anomalia de Chuva (IAC). Período Chuvoso. Período Seco. Variabilidade. Sudoeste.

\section{EVALUATION OF THE PRECIPITATION OF THE MICRO-REGION OF THE EASTERN PARAÍBA SERIDÓ}

\footnotetext{
Abstract

The Brazilian Northeast is characterized by have large irregularities in precipitation, which is one of the most important climatic variables. That is why

${ }^{1}$ Graduado em Ecologia pelo Departamento de Engenharia e Meio Ambiente (DEMA) da Universidade Federal da Paraíba (UFPB). E-mail: andre.lso1@hotmail.com

${ }^{2}$ Graduado em Ecologia pela Universidade Federal da Paraíba (UFPB) e Ciências Biológicas pelo Centro Universitário Leonardo da Vinci (UNIASSELVI). E-mail: gyo.vanne@hotmail.com 3 Graduado em Ecologia pelo Departamento de Engenharia e Meio Ambiente (DEMA) da Universidade Federal da Paraíba (UFPB). E-mail: walkimer.santana@hotmail.com 4 Professor Dr. do Departamento de Engenharia e Meio Ambiente (DEMA) da Universidade Federal da Paraíba (UFPB). E-mail: lincolneloi@yahoo.com.br
} 
we must know it, not only to characterize the continent's climate, but also to countless productive activities, such as agriculture, cattle raising, hydropower generation, among others. Therefore, the paper undertakes to evaluate the rainfall variability of the Eastern Serido Paraibano, through the monthly and annual space-time analysis of the rainfall and to identify the dry and rainy cycles of the studied area with the aid of the Rainfall Anomaly Index (IAC). For this, the rainfall data used in the research correspond to the rainfall series from 1994 to 2014 provided by the AESA for the spatial-temporal assessment of rainfall and for the calculation of the Rainfall Anomaly Index (IAC). The area presents two distinct periods, a wet period, which runs from January to June and a dry period from July to December. More precipitation was observed in the North West and South West parts, being in greater abundance in the South West region.

Keywords: Rain Anomaly Index (IAC). Rainy Period. Dry Period. Variability. South-west.

\section{EVALUACIÓN DE LA PRECIPITACIÓN DE LA MICRO-REGIÓN DEL PARAÍBA ORIENTAL SERIDÓ}

\section{Resumen}

El noreste de Brasil se caracteriza por tener grandes irregularidades en la precipitación, que es una de las variables climáticas más importantes. Es por eso que debemos conocerlo, no solo para caracterizar el clima del continente, sino también para planificar numerosas actividades productivas, como la agricultura, la ganadería, la generación de energía hidroeléctrica, entre otras. Por lo tanto, el trabajo se compromete a evaluar la variabilidad de la precipitación del Seridó Oriental Paraibano, a través del análisis espacial y temporal mensual y anual de la precipitación e identificar los ciclos secos y lluviosos del área estudiada con la ayuda del Índice de Anomalía de Lluvia (IAC). Para esto, los datos pluviométricos utilizados en la investigación corresponden a las series mensuales de precipitación pluviométrica en el período de 1994 a 2014 proporcionadas por AESA para la evaluación espacio-temporal de la precipitación y para el cálculo del Índice de Anomalía de Lluvia (IAC). Donde los dos años extremadamente secos fueron 1998 y 2012 y los 2 años extremadamente húmedos fueron 2009 y 2011. El área tiene dos períodos distintos, un período húmedo, que va de enero a junio y un período seco, de julio a diciembre. Se encontraron precipitaciones más concentradas en las partes noroeste y suroeste, siendo más abundantes en la región suroeste.

Palabras clave: Índice de anomalías de lluvia (IAC). Período lluvioso. Período seco. Variabilidad. Suroeste.

\section{INTRODUÇÃO}

O meio ambiente é constituído por um conjunto natural de constantes interações dos componentes bióticos e abióticos, por isso o clima de toda e qualquer região, situada nas mais diversas latitudes do globo, apresenta-se com 
características diferentes em cada ano (SORIANO, 1997). A precipitação, sendo um dos componentes abióticos, é uma das variáveis climáticas mais importantes, sendo assim, de acordo com Freitas et al (2010) conhecê-la é de grande importância, não só para caracterizar o clima do continente, mas também para planejar inúmeras atividades produtivas, tais como agricultura, pecuária, geração de energia hidrelétrica dentre outras.

O Nordeste brasileiro caracteriza-se por ter grandes irregularidades na precipitação e seu comportamento é resultante de um conjunto de fatores fisiográficos e de sistemas atmosféricos (ARAÚJO et al 2008). De acordo com Silva et al (2009) a precipitação pluviométrica no Nordeste brasileiro é decorrente do acoplamento de vários sistemas atmosféricos e de diversas escalas quase periódicos, por exemplo a Zona de Convergência Intertropical (UVO, 1989), os Vórtices Ciclônicos de Ar Superior (KOUSKY; GAN, 1981), os Sistemas Frontais (KOUSKY, 1979), e os Distúrbios de Leste (ESPINOZA, 1996), que podem ser modificados pelas características fisiográficas da região e por anomalias atmosféricas de escala planetária.

Segundo Araújo et al. (2008), estes fenômenos são considerados como fator prejudicial às localidades atingidas ou não, pois tanto podem provocar períodos de enchentes, como de secas. Por isso para Silva et al (2009), o monitoramento desses períodos pode ser executado por meio do emprego de índices. Através deles, pode-se desenvolver um sistema de acompanhamento das características dos períodos secos ou chuvosos.

Dentre esses, o Índice de Anomalia de Chuva (IAC) é uma metodologia que vem sendo aplicada e difundida no Nordeste do Brasil para caracterizar os períodos extremos (secos e chuvosos), assim como as diferentes intensidades desses eventos no tempo e no espaço, sendo utilizado como uma ferramenta para auxiliar o acompanhamento climático e a variabilidade pluviométrica de uma determinada área, que pode ser uma bacia hidrográfica, uma microrregião, mesorregião ou até mesmo um país, auxiliando no gerenciamento dos recursos hídricos (ASSIS et al 2015).

Por isso é de fundamental importância para o estudo, a utilização do IAC, pois ele proporciona o entendimento do comportamento e monitoramento da precipitação em uma determinada serei histórica estudada. Assim, pode-se 
identificar os períodos secos e úmidos de uma região, como foi feito nos trabalhos de Araujo et al (2009); dos Santos et al (2015); Silva et al (2017); Silva et al (2018).

Um ponto crucial no emprego de um índice como esse, assim como de qualquer outro índice climático, reside na escolha do patamar a ser estabelecido para a definição de um período de seca. Nesse sentido, Freitas (2004 e 2005), observou que com base no mesmo é possível fazer uma comparação das condições atuais de precipitação em relação aos valores históricos, servindo ainda para avaliar a distribuição espacial do evento, consoante sua intensidade.

Apesar de a variabilidade ser um componente conhecido da dinâmica climática, seu impacto, pode ter reflexos significativos em diversas atividades humanas, como agropecuária, indústria e produção de energia, entre tanto, as sociedades e os recursos tecnológicos estão levemente adaptados a certo grau de variabilidade climática, além disso, as anomalias podem provocar desestruturação no sistema ambiental e socioeconômico (NUNES; LOMBARDO, 1995).

De acordo com Araújo; Silva (2011) o IAC necessita apenas de dados de precipitação, é facilmente calculado e visa tornar o desvio da precipitação, em relação à condição normal de diversas regiões. Segundo Repelli et al. (1998), o IAC parece ser adequado para utilização em regiões semiáridas e ou tropicais, inclusive para o Nordeste Brasileiro. Para Azevedo; Silva (1994) o monitoramento regional ou estadual do índice de seca pode ter várias utilidades, tais como: proporcionar às autoridades de planejamento uma ideia do grau de anormalidade relativa às condições do tempo e do clima na região; definir melhores épocas de plantio; avaliar as disponibilidades hídricas do solo e verificar a eficiência do sistema de abastecimento de água para os reservatórios.

Prever e monitorar, tanto os períodos secos ou chuvosos como a variabilidade espaço-temporal da precipitação no Nordeste brasileiro são de extrema importância devido a aspectos como: a existência de uma grande quantidade de projetos de irrigação implantados e que serão implantados durante os principais rios; o abastecimento de água das grandes cidades depende diretamente do escoamento dos rios, ou indiretamente do volume acumulado nas barragens; a maioria das culturas agrícolas é dependente da 
regularidade das chuvas e a possibilidade de uso de água subterrânea é pequena quando comparada ao da água superficial (FREITAS, 2005).

Os períodos secos e chuvosos influenciam ambientes construídos como o ambiente urbano, ou seja, a cidade. De acordo com Adler; Tanner (2015) a estrutura física da paisagem urbana tem pouca área com vegetação e muitas superfícies duras e impermeáveis à água. Por tanto, se tem mais superfícies impermeáveis consequentemente ocorrerá enchentes em períodos chuvosos, uma vez que, essa água que precipita não tem por onde infiltrar e permanece sobre $\mathrm{o}$ asfalto na maioria das vezes.

Diante de todas as abordagens apresentadas, esse trabalho tem como objetivo avaliar a variabilidade da precipitação do Seridó Oriental Paraibano, através da análise espaço-temporal mensal e anual da precipitação; e identificar os ciclos secos e chuvosos da área estudada com o auxílio do Índice de Anomalia de Chuva (IAC).

\section{METODOLOGIA}

A Microrregião do Seridó Oriental Paraibano localiza-se no Estado da Paraíba (Figura 1 A), na mesorregião da Borborema, entre o Sertão e o Agreste, na qual abrangem uma área de 2.608,722 km2 e população de 78.186 mil pessoas (IBGE, 2010). "Compreendida entre as latitudes $7^{\circ} 11^{\prime} 22.50^{\prime}$ e $6^{\circ} 16^{\prime} 52.33^{\prime \prime s u l ~ e ~ a s ~ l o n g i t u d e s ~} 36^{\circ} 42^{\prime} 4.32^{\prime \prime}$ e $36^{\circ} 13^{\prime} 8.70^{\prime \prime}$ oeste de Greenwich. É composta por nove municípios (Baraúnas, Cubati, Frei Martinho, Juazeirinho, Nova Palmeira, Pedra Lavada, Picuí, Seridó e Tenório) que representam a Microrregião (Figura 1 B). 
Figura 1 - Localização da Microrregião do Seridó Oriental Paraibano (A) e municípios que compõem a área de estudo (B)
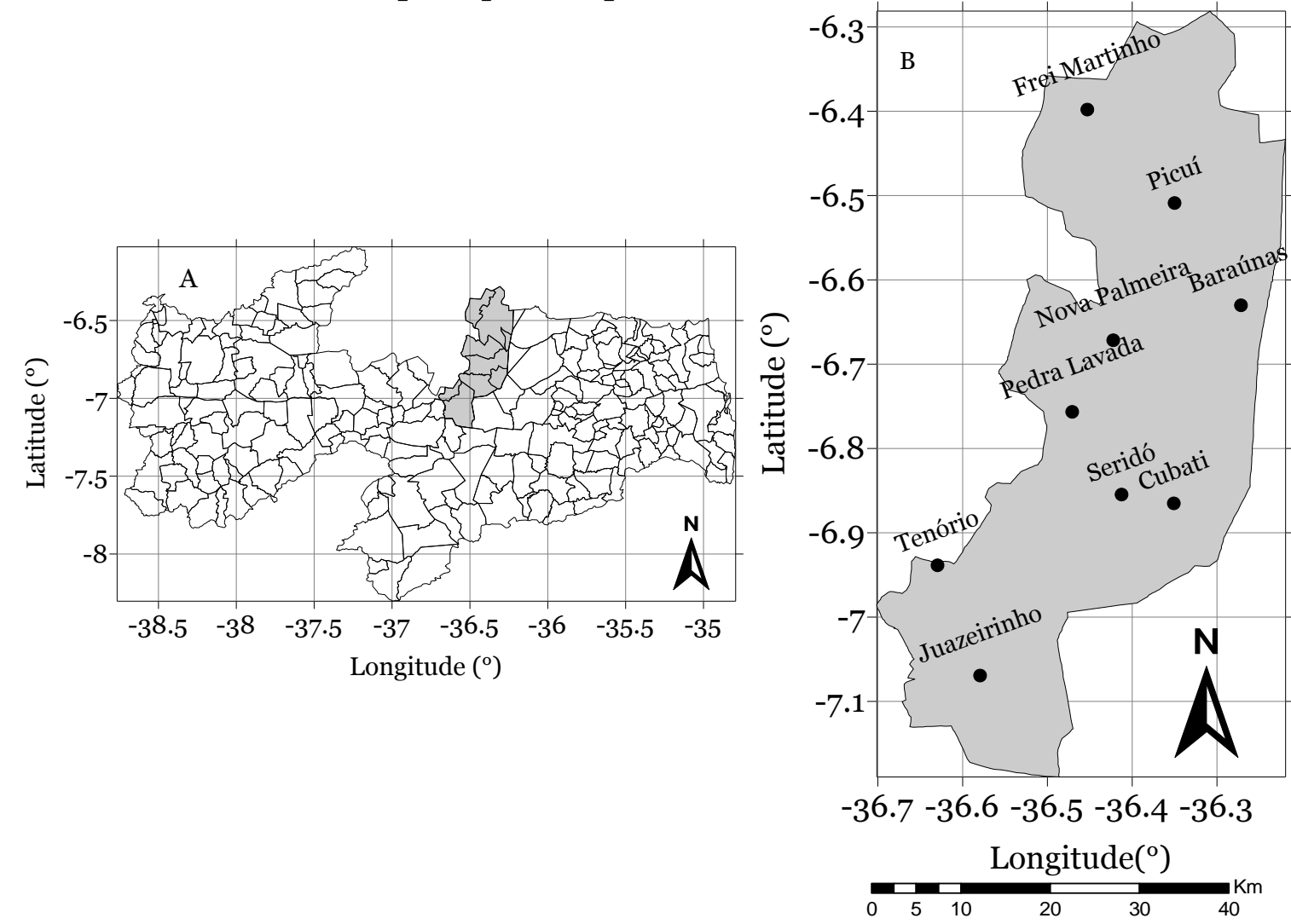

Fonte: Elaborado pelos autores.

Segundo Nascimento e Alves (2010) o clima do Seridó paraibano varia de semiáridos a sub-áridos, secos e tropicais, sendo caracterizado por uma pluviometria que se concentra em um período de 3 a 5 meses, com médias anuais de 569 milímetros, irregularmente distribuídas no tempo e no espaço. Apresenta temperaturas médias anuais elevadas, com mínima de 16 a $25^{\circ} \mathrm{C}$ e a máxima podendo chegar a $33^{\circ} \mathrm{C}$.

Os dados pluviométricos utilizados na pesquisa correspondem às séries mensais de precipitação pluviométrica no período de 1994 a 2014 fornecidos pela AESA (Agência Executiva de Gestões das Águas do Estado da Paraíba) para a avaliação espaço-temporal da precipitação e para o cálculo do Índice de Anomalia de Chuva (IAC), o qual foi adaptado por Freitas (2005) e readaptado por Araújo et al. (2009) no intuito de caracterizar os períodos secos ou úmidos, e analisar as contribuições dos períodos chuvosos. 
Para a avaliação espaço-temporal foi utilizada a planilha de dados disponibilizada pela AESA, onde foi calculada a média mensal de precipitação de cada município da microrregião. A partir desses valores foi possível calcular a média anual, por meio da soma da média de todos os meses e dividida pelo total de meses do ano. Depois, criou-se uma planilha com as médias mensais e anuais de cada município para poder gerar por meio da interpolação dos dados a espacialização da precipitação acumulada e mensais da região, neste processo foi utilizado o programa de interpolação de dados Surfer.

A avaliação do grau de severidade e duração dos períodos secos e úmidos foi feita por meio do cálculo do IAC, (FREITAS, 2004, 2005), obtido a partir das equações:

$$
\begin{aligned}
\mathrm{IAC} & =3\left[\frac{(N-\bar{N})}{(\bar{M}-\bar{N})}\right]: \text { Para anomalias positivas } \\
\mathrm{IAC} & =-3\left[\frac{(N-\bar{N})}{(\bar{X}-\bar{N})}\right]: \text { Para anomalias negativas }
\end{aligned}
$$

Em que:

$\mathrm{N}$ = precipitação mensal atual $(\mathrm{mm})$;

$\bar{N}=$ precipitação média mensal da série histórica $(\mathrm{mm})$;

$\bar{M}=$ média das dez maiores precipitações mensal da série histórica (mm);

$\bar{X}=$ média das dez menores precipitações mensais da série histórica $(\mathrm{mm})$.

Foram obtidos dados de 09 (nove) postos pluviométricos distribuídos na microrregião, dos quais foi disponibilizada uma série histórica de 21 anos. Conforme a climatologia, uma série como esta é considerada bastante curta, no entanto, de acordo com Santos et al (2011) apesar de ser curta, permite formular hipóteses sobre tendências de aumento ou redução das chuvas em condições atmosféricas extremas. Conforme os mesmos, para a aplicação do IAC é recomendável à utilização de séries históricas com pelo menos 30 anos de dados. Caso a série em questão tenha menos de 30 anos de dados, faz-se necessária uma adaptação no cálculo do IAC, no qual deve ser modificada de maneira a se tornar proporcional à quantidade de dados disponíveis; assim, 
deve-se fazer uma regra de três simples onde, em uma série de 21 anos de dados, por exemplo, ao invés de utilizar as 10 médias maiores ou menores, utiliza-se as médias das 7 maiores ou 7 menores precipitações totais do período analisado. A partir da metodologia de Freitas (2004 e 2005), readaptada por Araújo et al (2009) para uma nova classificação de anos secos e úmidos será utilizada a Tabela 1 para classificar os anos estudados.

Tabela 1 - Classes de intensidades do índice de anomalia de chuva (IAC) da Microrregião do Seridó Oriental Paraibano.

\begin{tabular}{lll}
\hline & FAIXA DO IAC & CLASSES DE INTENSIDADE \\
\hline \multirow{2}{*}{ Índice } & De 4 acima & Extremamente úmido \\
De anomalia & 2 a 4 & Muito úmido \\
De chuva & o a 2 & Úmido \\
(IAC) & o a -2 & Seco \\
& -2 a -4 & Muito seco \\
& De -4 abaixo & Extremamente seco \\
\hline
\end{tabular}

Fonte: Araújo et al (2009).

E por fim, no intuito de melhor avaliar a variabilidade temporal da precipitação e observar as diferenças entre os períodos secos e chuvosos, foram analisados anos específicos da série histórica e selecionados dois anos secos e dois anos úmidos mais significativos. A escolha específica desses anos deve-se ao fato de serem anos extremos (extremamente secos e extremamente úmidos, respectivamente) com relação aos demais anos da série histórica.

\section{RESULTADOS E DISCUSSÃo}

A variabilidade temporal da precipitação da Microrregião do Seridó Oriental Paraibano evidencia-se com seis meses úmidos, e seis meses de precipitação abaixo da média, com precipitação média mensal de $39,1 \mathrm{~mm}$ (Figura 02). O período chuvoso compreende os meses de janeiro a junho, no qual março é o mês mais significativo com média de $99,3 \mathrm{~mm}$, associado à atuação da ZCIT - Zona de Convergência Intertropical, que atua favorecendo a região estudada entre fevereiro e maio, ocasionando uma maior precipitação no mês de março (ARAÚJO, 2010). O período seco ocorre entre os meses de julho a dezembro, sendo novembro o mês mais seco com média de $3,5 \mathrm{~mm}$. Segundo Oliveira; Pereira (2015) o Seridó apresenta baixos índices de precipitação, 
fazendo com que a atividade agrícola, o abastecimento hídrico, a fauna, flora e o solo sofram as consequências dessas limitações climáticas.

Figura 2 - Pluviograma mensal da Microrregião do Seridó Oriental Paraibano (serie histórica de 21 anos)

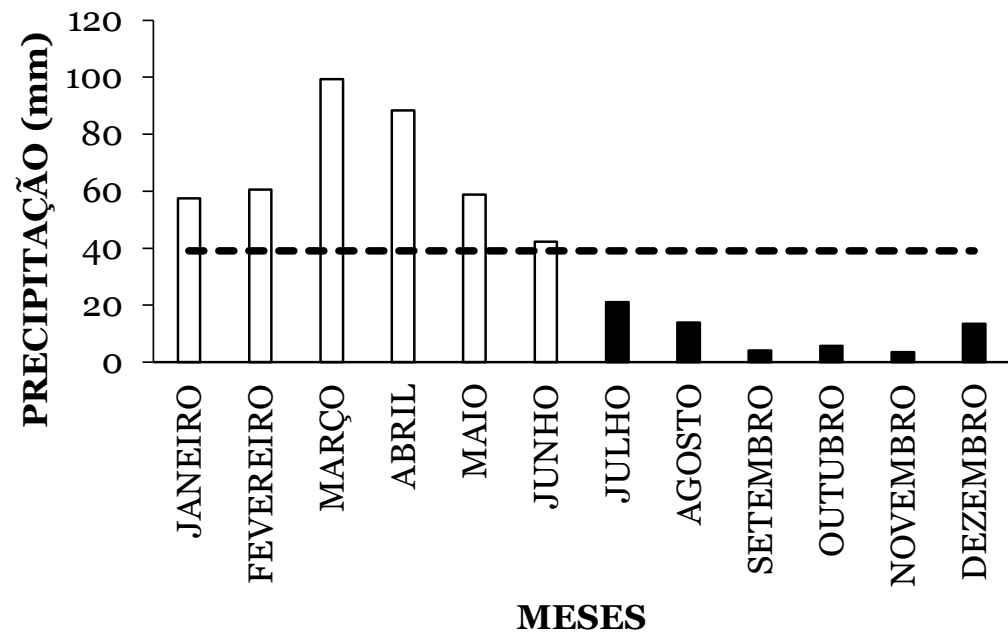

Fonte: Elaborado pelos autores.

Ressalta-se também que segundo Medeiros et al (2003) para o município de Picuí a distribuição das chuvas durante o ano está concentrada no período de fevereiro a abril, chegando às vezes até o mês de junho, começando a partir daí a escassez das precipitações pluviais a tal ponto que de setembro a dezembro praticamente não ocorre nenhuma chuva. Desta forma, observa-se que por fazer parte da microrregião em estudo, o município de Picuí apresentou resultados semelhantes aos encontrados neste presente trabalho, o que corrobora com o presente estudo.

A Microrregião do Seridó Oriental Paraibano apresentou no período chuvoso a predominância de $87 \%$ da precipitação anual, já no período seco, os demais $13 \%$ da precipitação (Figura 3). 
Figura 3 - Representação percentual da precipitação da Microrregião do Seridó Oriental Paraibano

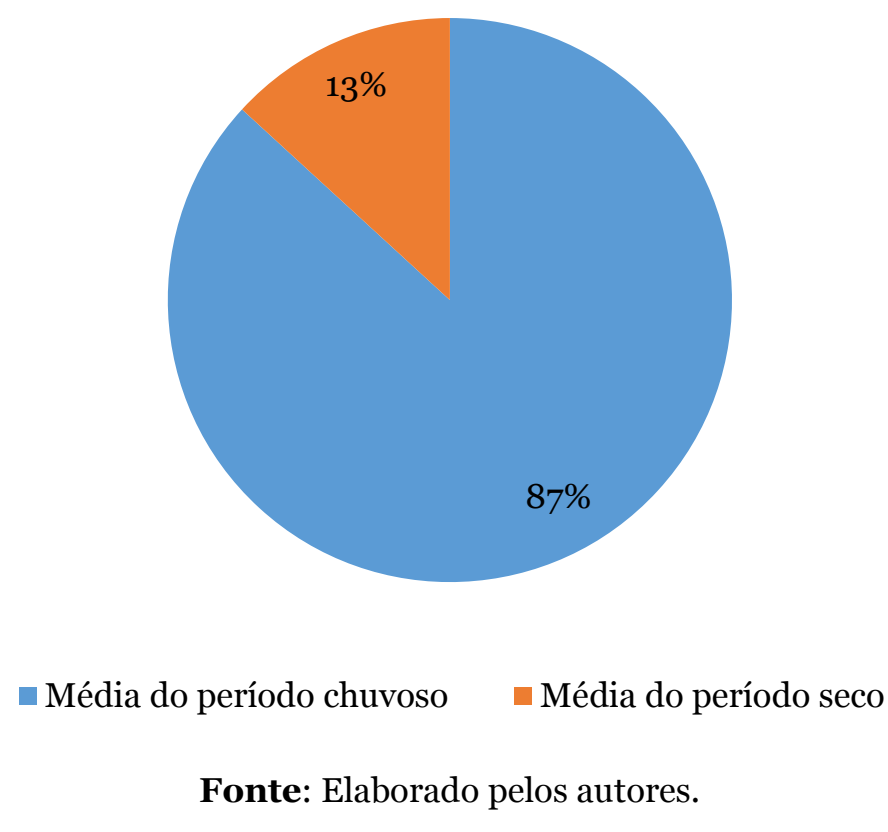

Os valores acumulados de precipitação da microrregião do Seridó Oriental Paraibano variam de 400 a 540 milímetros por ano, sendo que os maiores valores concentram-se na área Noroeste e Sudoeste da Microrregião. Em contrapartida, as regiões Nordeste e Sudeste apresentam valores baixos de precipitação, com os menores, principalmente no setor Leste (Figura 4). 
Figura 4 - Acumulado espacial da precipitação (mm)

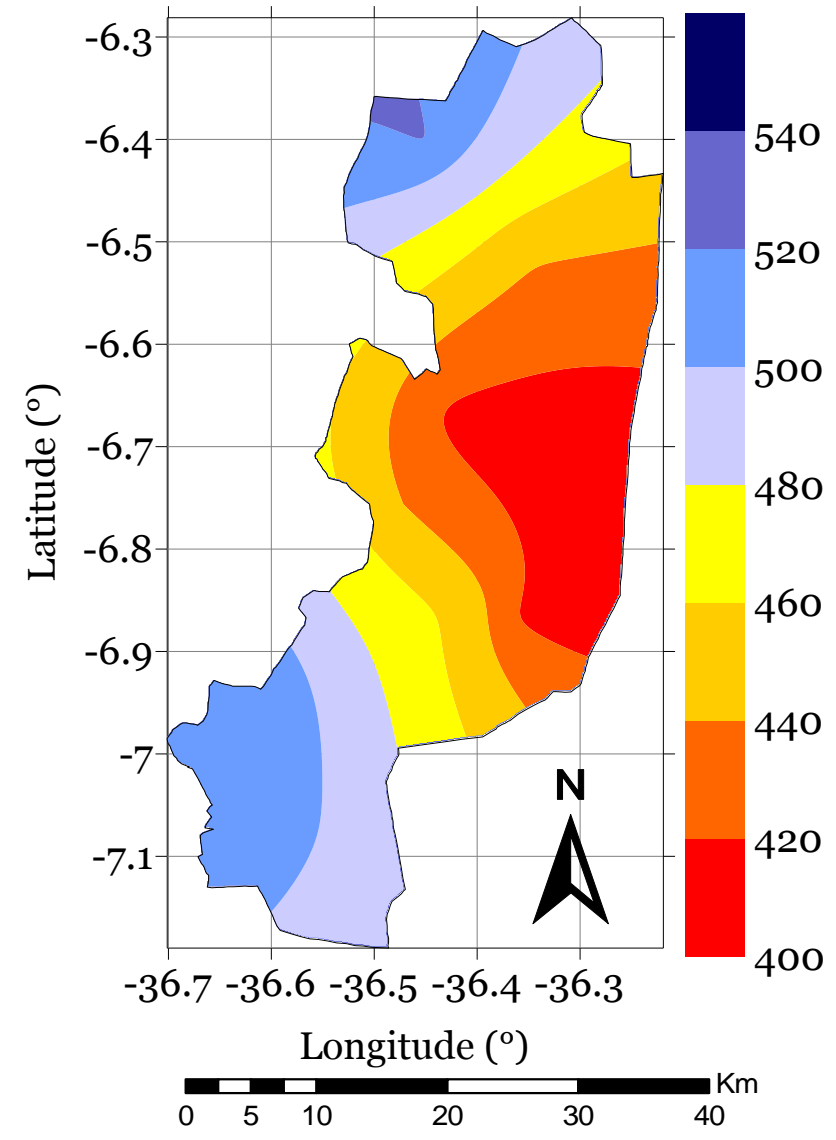

Fonte: Elaborado pelos autores.

A variabilidade espacial mensal da precipitação da microrregião do Seridó Oriental Paraibano é observada nas isoietas médias mensais da região estudada, como demonstrada nas Figuras de 5 e 6. 
Figura 5 - Espacialização das chuvas (mm) da microrregião do Seridó Oriental Paraibano de Janeiro (A), Fevereiro (B), Março (C), Abril (D), Maio (E) e Junho (F)

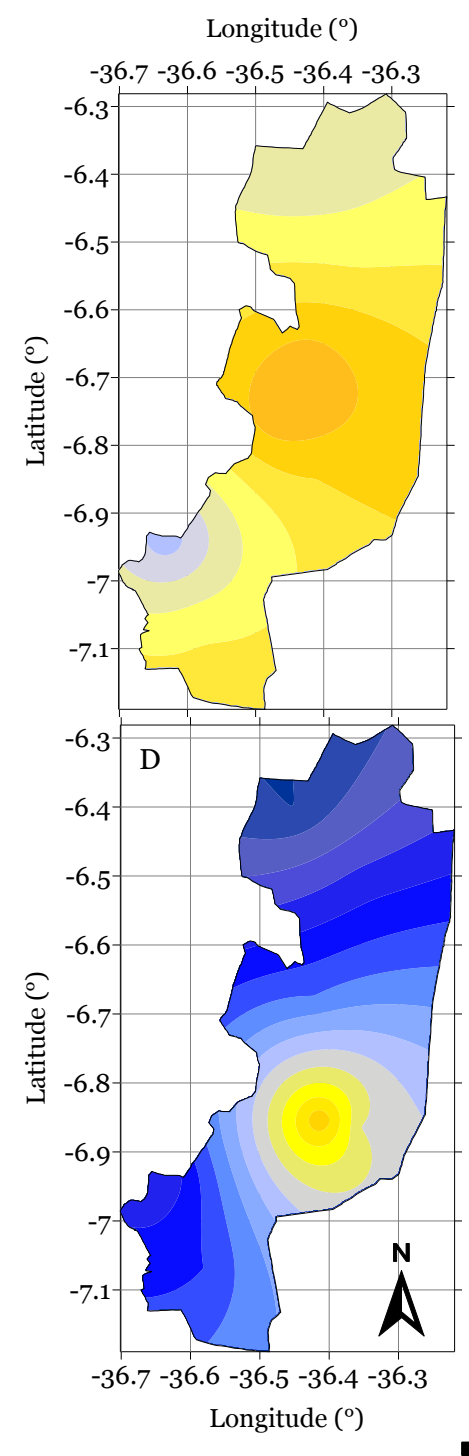

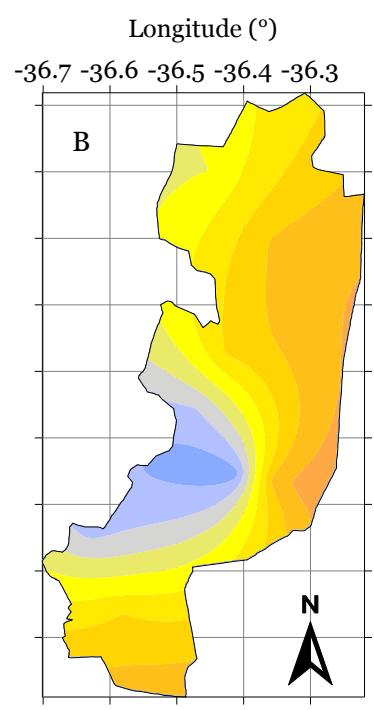

$-36.7-36.6-36.5-36.4-36.3$

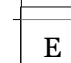

E

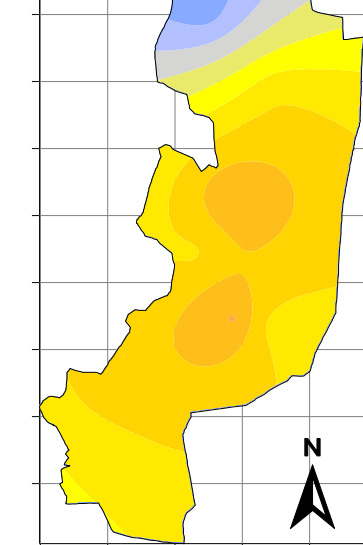

$-36.7-36.6-36.5-36.4-36.3$

Longitude $\left({ }^{\circ}\right)$
Longitude $\left({ }^{\circ}\right)$

$-36.7-36.6-36.5-36.4-36.3$
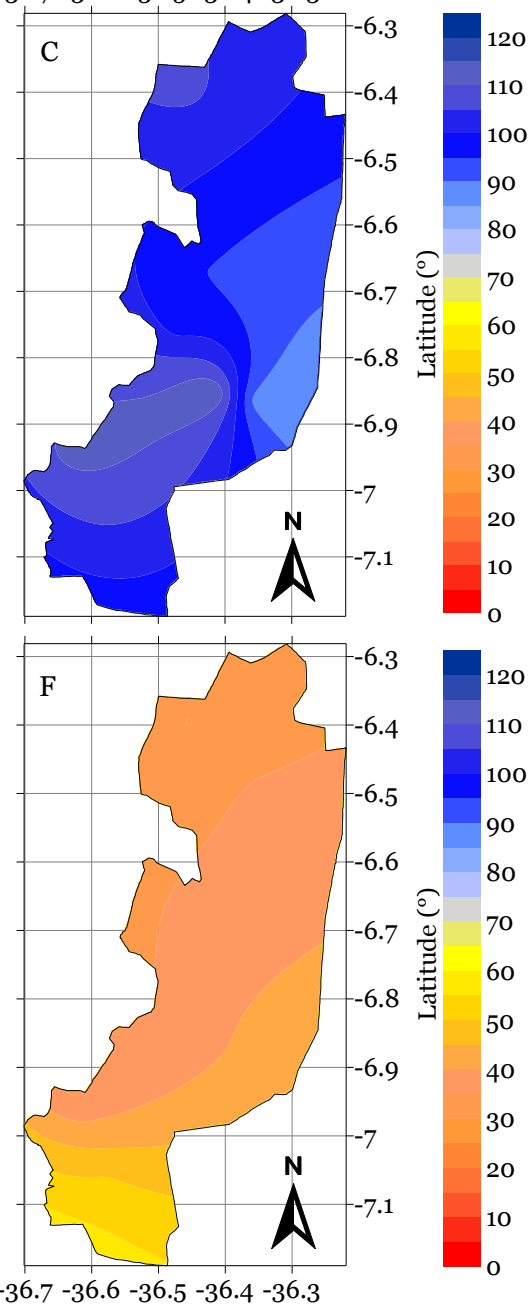

F Longitude $\left({ }^{\circ}\right)$

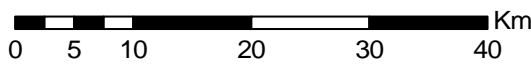

Fonte: Elaborado pelos autores. 
Figura 6 - Espacialização das chuvas $(\mathrm{mm})$ da microrregião do Seridó Oriental Paraibano de julho $(\mathrm{G})$, agosto $(\mathrm{H})$, setembro (I), outubro (J), novembro (K) e dezembro (L)
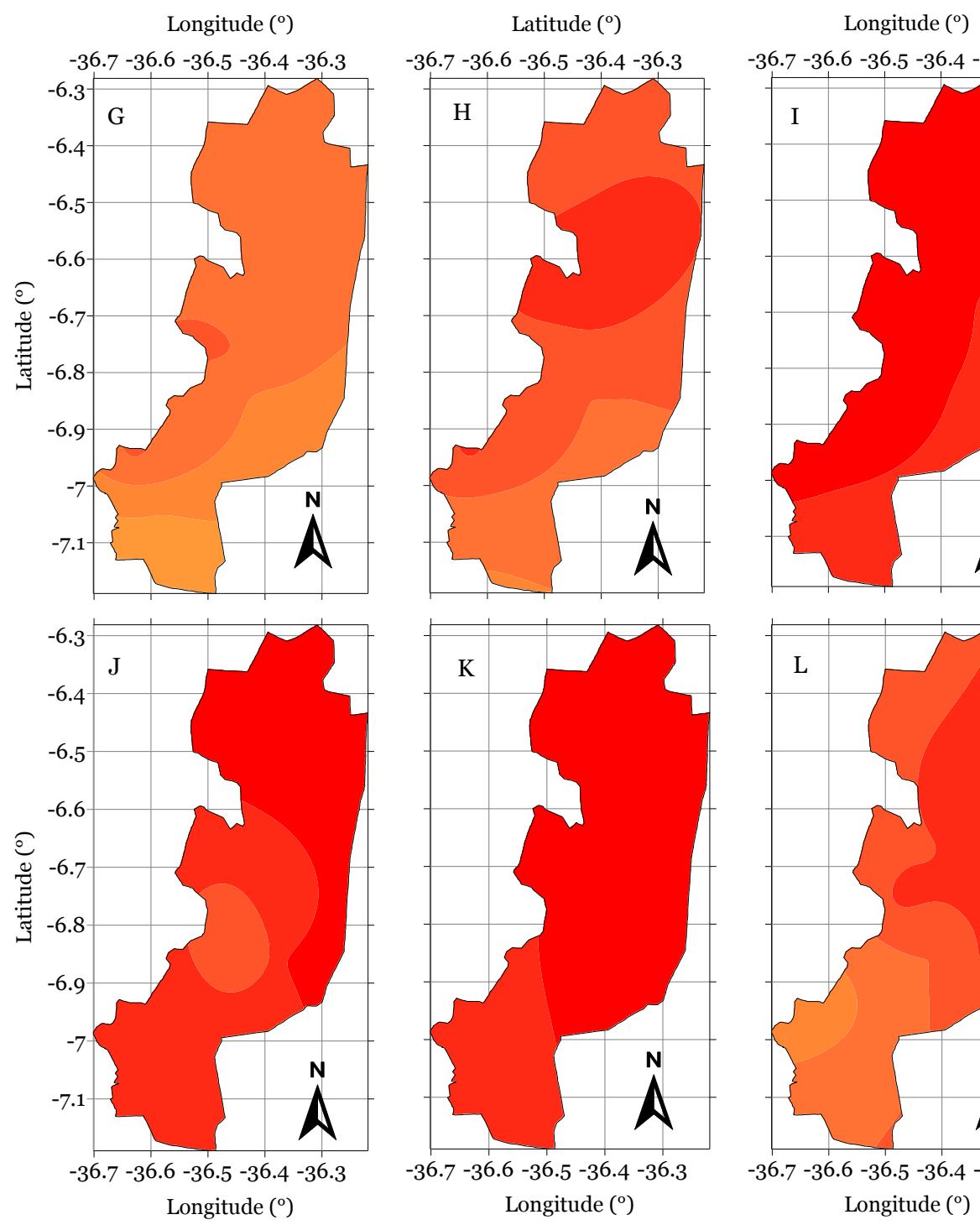

$-36.7-36.6-36.5-36.4-36.3$
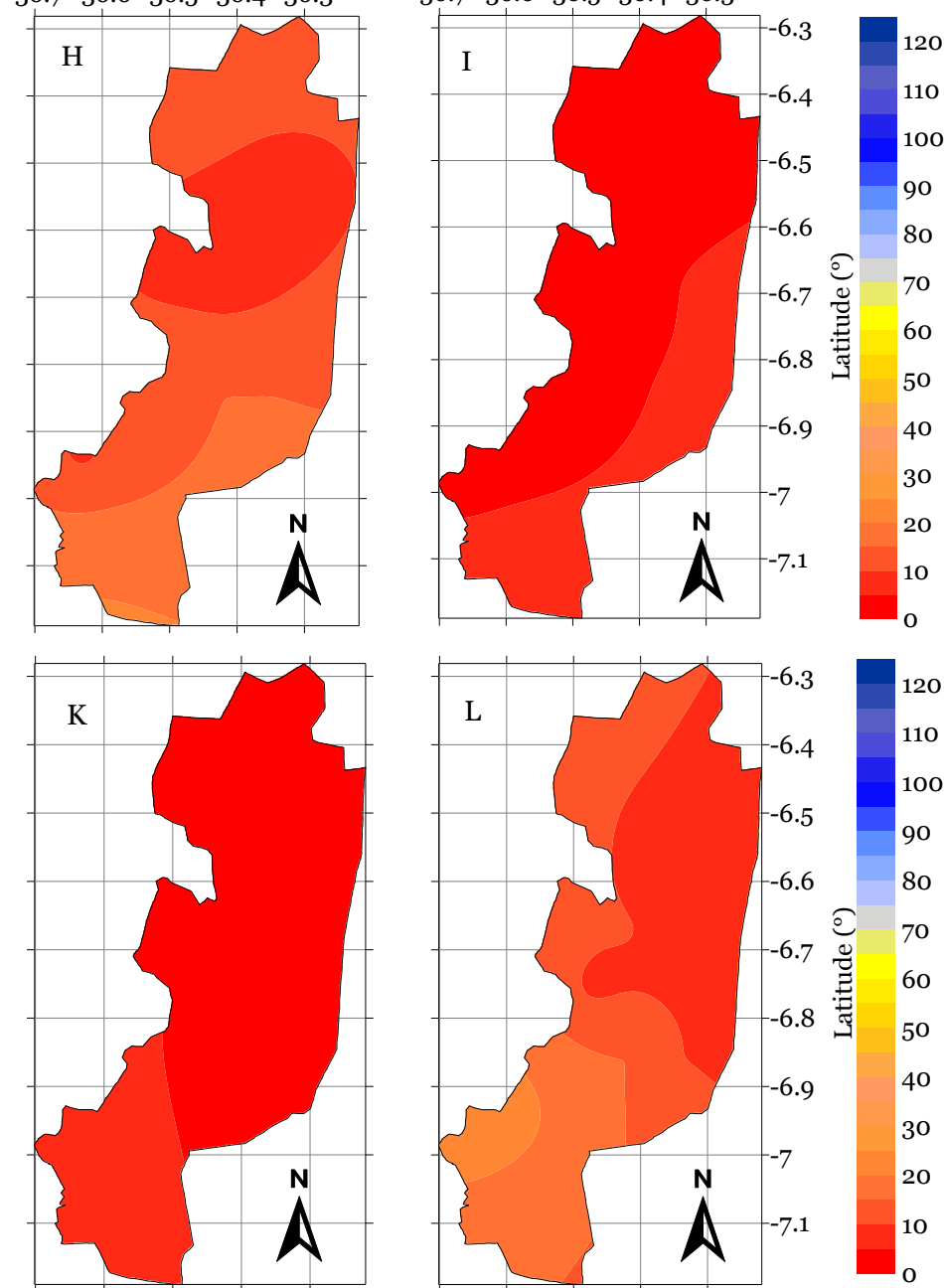

$-36.7-36.6-36.5-36.4-36.3$ Longitude $\left(^{\circ}\right)$

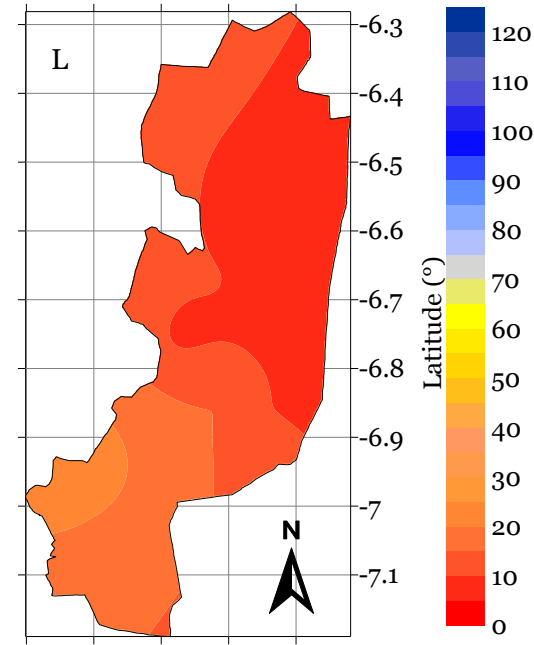

$-36.7-36.6-36.5-36.4-36.3$ Longitude $\left({ }^{\circ}\right)$

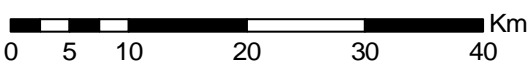

Fonte: Elaborado pelos autores.

O mês de janeiro (A) mostra a transição da estação mais seca para a estação mais chuvosa da microrregião do Seridó Oriental Paraibano, com valores máximos de $78 \mathrm{~mm}$ na região sudoeste e valores menores de $43 \mathrm{~mm}$ na região centro oeste da microrregião. O mês de fevereiro (B) apresentou-se de forma similar, com uma distribuição mais abrangente, maiores valores ficaram 
distribuídos na região sudoeste. Os menores valores de precipitação ocorrem da região sudeste para o nordeste.

O mês de março (C) foi considerado o maior representante em termos de precipitação na região, com valores de 79 a $114 \mathrm{~mm}$, sendo que os maiores valores de precipitação concentram-se na região sudoeste e os menores na região sudeste. De acordo com Araújo (2006), é nesse quadrimestre que as maiores chuvas se centralizam por causa da atuação dos principais sistemas meteorológicos atuantes nesses meses, como os Vórtices Ciclônicos de $\mathrm{Ar}$ Superior (VCAS) e a Zona de Convergência Intertropical (ZCIT). O mês de abril (D) apresentou-se de forma similar, entretanto, teve maiores valores na região noroeste com valores de até $120 \mathrm{~mm}$ e menores valores na região sudeste com $50 \mathrm{~mm}$ de precipitação. Corroborando com o autor anterior, Costa et al (2013), se propôs a fazer um estudo sobre a precipitação do Seridó Paraibano, no qual os maiores volumes pluviométricos estão entre março e abril, mostrando também uma certa similaridade aos resultados obtidos no presente trabalho.

O mês de maio (E) mostra a transição da estação chuvosa para a estação seca da microrregião do Seridó Oriental Paraibano, com valores máximos de precipitação de $83 \mathrm{~mm}$ na região norte e noroeste e valores mínimos de precipitação de $44 \mathrm{~mm}$ na região centro oeste da microrregião. $\mathrm{O}$ mês de junho (F) apresentou-se com uma distribuição de valores baixos de 30 a $40 \mathrm{~mm}$ de precipitação em quase toda a área estudada e os maiores valores ficaram distribuídos na região sul e os menores valores ocorram nas regiões, norte, noroeste e oeste.

O mês de julho (G) mostra valores máximos de precipitação de $25 \mathrm{~mm}$ na região sul e sudoeste e valores mínimos de precipitação de $12 \mathrm{~mm}$ nas regiões leste, norte e oeste da microrregião. $\mathrm{O}$ mês de agosto $(\mathrm{H})$ apresentou-se com uma distribuição abarcante de valores baixos de o a $24 \mathrm{~mm}$ de precipitação, os maiores valores distribuíram-se nas regiões sul e sudeste e os menores valores ocorreram nas regiões leste, nordeste e oeste.

O mês de setembro (I) mostra a estação mais seca da microrregião do Seridó Oriental Paraibano, com valores abaixo de $10 \mathrm{~mm}$ em toda a região. Outubro $(J)$ se comporta de forma similar ao mês de setembro com maiores 
valores na região centro oeste e menores valores na região sul, noroeste, norte e nordeste.

Novembro (K), assim como setembro e outubro, também é caracterizado mês seco, por ter precipitações inferiores a $10 \mathrm{~mm}$ em toda região, ou seja, chove abaixo da média. Corroborando com Costa et al (2013), que encontrou um menor valor de precipitação no mês de outubro, porém, o mês menos significativo foi novembro. E por fim, o mês de dezembro (L) apresentou-se com valores mínimos de 5 a 24 mm de precipitação, os maiores valores distribuíramse nas regiões sul e sudoeste e menores valores ocorreram nas regiões leste, nordeste, norte.

Nota-se que de setembro a novembro ocorre a estação mais seca da microrregião, por tanto, são os meses com maior escassez hídrica. De acordo com Araújo (2010), os meses mais peculiares de todo o ano, ou seja, com menor precipitação, precisam de uma maior atenção para as reservas hídricas e os desperdícios em toda área de estudo.

Assim, para melhor avaliar a variabilidade da precipitação aplicou-se o índice de anomalia de chuva (IAC) na região de estudo. Este índice corresponde as médias mensais e anuais das precipitações na serie histórica estudada, neste sentido podemos observar a partir dessas médias, os anos que tiveram precipitações superiores e os anos que foram inferiores, ás medias atingidas por ano. Diante disso, encontrou-se uma predominância de valores positivos com 11 anos úmidos, variando entre as classes de úmido (1994, 1995, 2002, 2005, 2006 e 2010), muito úmido (2000, 2004, 2008 e 2011) ou extremamente úmido (2009). E em contrapartida foi observado valores negativos em 10 anos secos ao longo da série, cuja classificação sugere ano seco (1996, 1997, 2003, 2007 e 2014), muito seco (1999, 2001 e 2013) ou extremamente seco (1998 e 2012), conforme Figura 7. 
Figura 7 - Índice de anomalia de chuva (IAC) da Microrregião do Seridó Oriental Paraibano

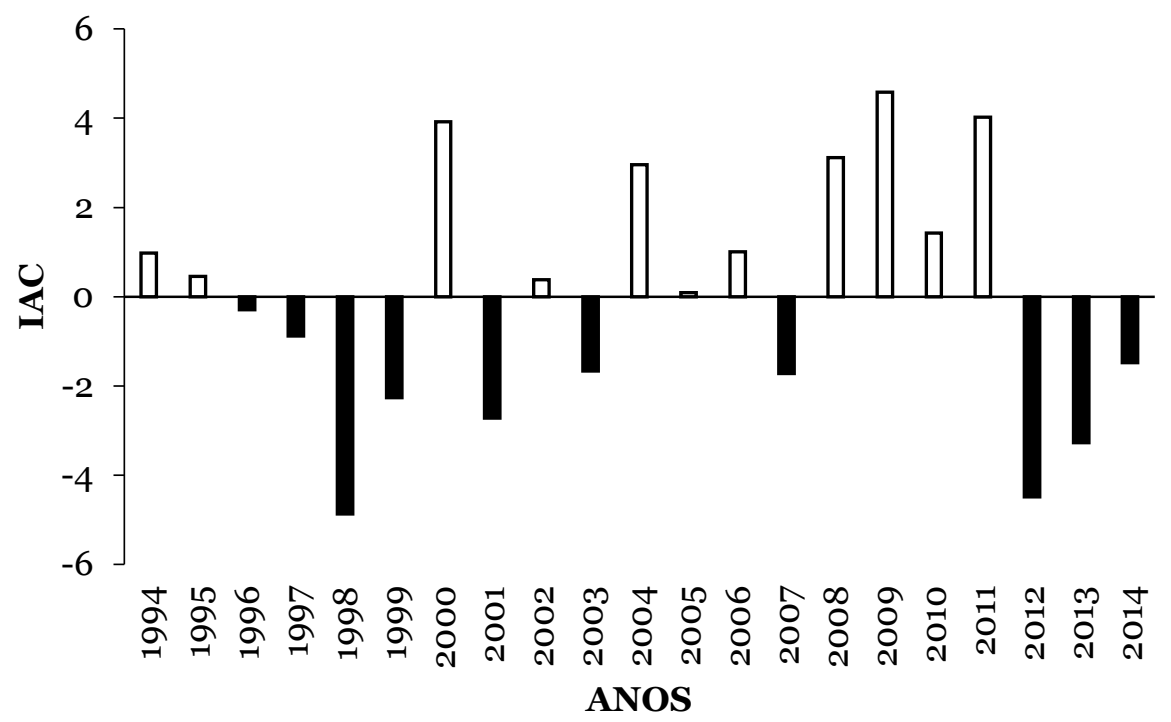

Fonte: Elaborado pelos autores.

Embora a série seja relativamente curta, observa-se uma variação entre os anos secos e úmidos com ocorrência de quatro anos consecutivos de um período para outro. Sendo que de 1996 a 2003 ocorre uma predominância de anos secos. Já entre os anos de 2004 e 2011 ocorre uma predominância de anos úmidos, ou seja, ocorrem anomalias. Segundo Souza (2014), essas anomalias causam grandes impactos à sociedade, à economia e ao meio ambiente, e estes podem variar desde secas até enchentes.

O índice de anomalia de chuva (IAC) da Microrregião do Seridó Oriental Paraibano para os anos secos de 1998 e 2012 é demonstrado na Figura o8. É possível identificar no período seco (julho a dezembro) que os meses de julho e agosto de 1998 apresentaram-se com valor de IAC positivo. Já no período úmido, de janeiro a junho, quatro meses apresentaram-se negativos, no qual, março, abril e maio para o ano de 2012 e para 1998 os meses de abril, maio e junho. Apesar de serem dois anos classificados como extremamente seco, evidencia-se que existe a ocorrência significativa de precipitação.

De acordo com Santos (1998), as secas apresentam consequências diretas e indiretas: destacam-se nas consequências diretas a falta de fornecimento de água para a população, perda na agricultura, indústria e produção de energia 
hidroelétrica, além de apresentar limitações na navegação dos rios e a pesca em águas interiores. Para as consequências indiretas encontram-se os incêndios e problemas florestais, problemas fitossanitários, maior concentração de poluentes nos meios hídricos e consequentemente a deterioração da qualidade da água e a erosão do solo.

Figura 8 - Índice de anomalia de chuva (IAC) mensal de anos secos da Microrregião do Seridó Oriental Paraibano

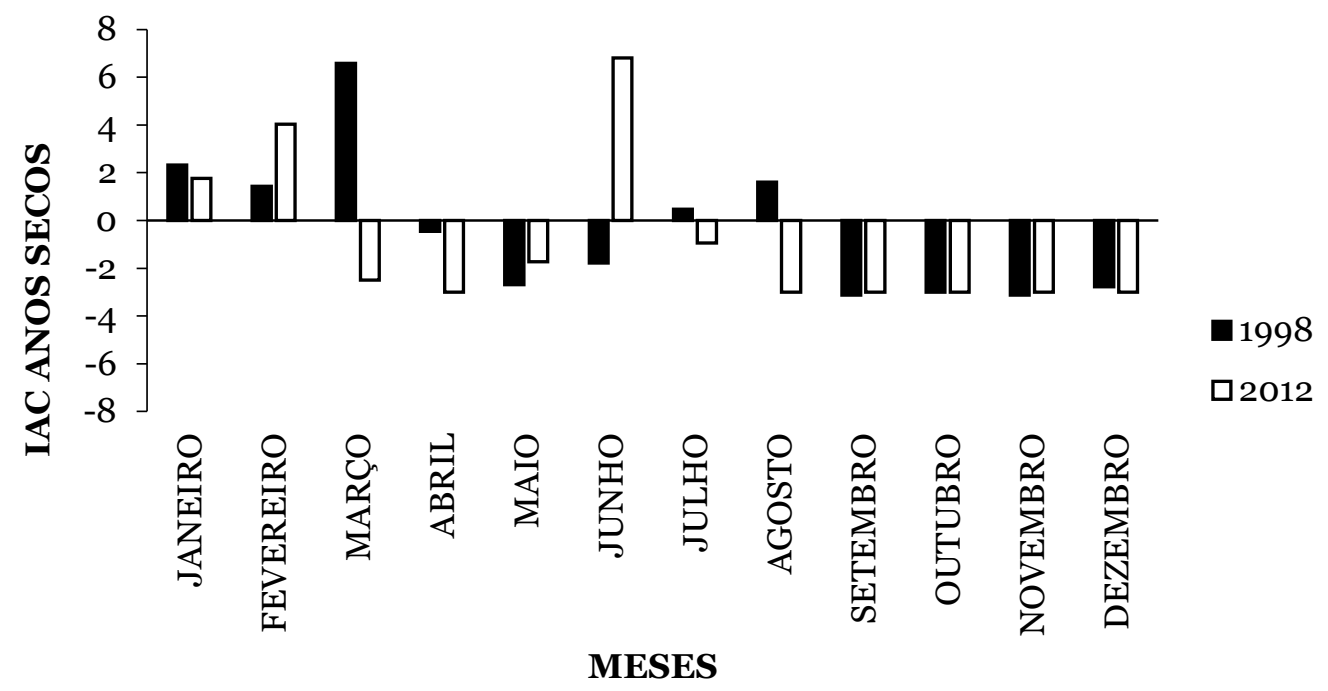

Fonte: Elaborado pelos autores.

O índice de anomalia de chuva (IAC) da Microrregião do Seridó Oriental Paraibano para os anos úmidos de 2009 e 2011 (Figura 09), anos em que o IAC apresentou-se positivo. É possível identificar no período seco (julho - dezembro) que apenas o mês de julho no ano de 2011 apresentou-se com valor de IAC positivo. Já no período úmido (janeiro a junho), apresentaram-se com IAC negativos os meses de janeiro e junho para o ano de 2009 e para o ano de 2011, apenas o mês de junho. 
Figura 9 - Índice de anomalia de chuva (IAC) mensal de anos úmidos da Microrregião do Seridó Oriental Paraibano

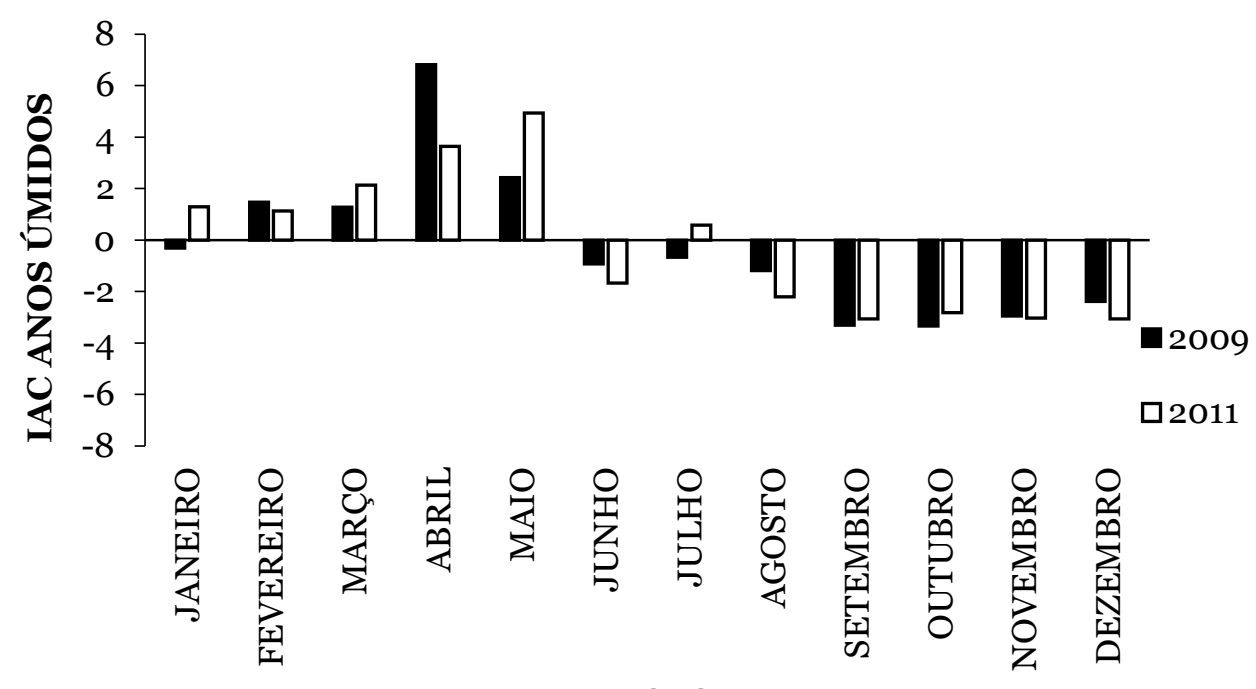

MESES

Fonte: Elaborado pelos autores.

\section{CONSIDERAÇÕES FINAIS}

A variabilidade temporal da precipitação da Microrregião do Seridó Oriental Paraibano evidencia-se com seis meses chuvosos, de janeiro a junho e seis meses secos, de julho a dezembro. Os maiores valores da precipitação são observados nos setores Noroeste e Sudoeste, em contrapartida a região nordeste, leste e sudeste apresentam-se com valores baixos.

Destaca-se também, a alternância no padrão da distribuição espacial da precipitação na microrregião do Seridó Oriental Paraibano, entre os meses de março e abril, apresentando um aumento no setor norte e sudoeste e uma redução das chuvas a sudeste para o nordeste. E também para os meses de outubro e novembro com um aumento quase imperceptível na região sudoeste e menores valores em praticamente toda região, principalmente no mês de novembro.

Por fim, ocorre uma variação entre os anos secos e úmidos com ocorrência de quatro anos consecutivos de um período para outro. Sendo que de 1996 a 2003 ocorre uma predominância de anos secos. Já de 2004 a 2011 ocorre uma predominância de anos úmidos. Mostrando assim um equilíbrio nas 
alternâncias de precipitação de quatro em quatro anos, viabilizando a dinâmica ecológica da área de estudo entre clima, fauna, flora e demais atividades humanas.

\section{REFERÊNCIAS}

ADLER, F. R; TANNER, C. J. Ecossistemas urbanos: Princípios Ecológicos para o Ambiente Construído. São Paulo: Oficina de textos, 2015 .

ARAÚJO, L. E. Análise estatística de chuvas intensas na bacia hidrográfica do rio Paraíba. Dissertação de mestrado. UFCG. 2006.

ARAÚJO, L. E. Climatologia e Vulnerabilidade Socioeconômica e Ambiental da Bacia Hidrográfica do Rio Paraíba - Estudo de Caso do Açude Epitácio Pessoa (Boqueirão), 2010. 120f. Tese (Doutorado em Recursos Naturais) Universidade Federal de Campina Grande, Campina Grande, março de 2010.

ARAÚJO, L. E.; MORAES NETO, J. M.; SOUSA, F. A. S. Classificação da precipitação anual e da quadra chuvosa da bacia do rio Paraíba utilizando índice de Anomalia de Chuva (IAC). Ambi-Agua, Taubaté, v. 4, n. 3, p. 93-110, 2009.

ARAÚJO, L. E; SILVA, D. Influência da variabilidade climática sobre a distribuição espaço-temporal da precipitação no Baixo Paraíba (PB). Caminhos de Geografia, v.12, p. 289-304, 2011.

ARAÚJO, L. E; SOUSA, F. A. S.; RIBEIRO, M. A. F. M.; SANTOS, A. S.; MEDEIROS, P. C. Análise estatística de chuvas intensas na bacia hidrográfica do Rio Paraíba. Revista Brasileira de Meteorologia, v.23, n.2, p. 162-169, 2008.

ASSIS, J. M. O.; SOUZA, W. M.; SOBRAL, M. C. M. Climate analysis of the rainfall in the lower-middle stretch of the São Francisco river basin based on the rain anomaly index. Revista Brasileira de Ciências Ambientais, v. 2, p. 188-202, 2015.

AZEVEDO, P. V; SILVA, V. P. R; Índice de seca para a microrregião do agreste da Borborema, no estado da Paraíba. Revista Brasileira de Meteorologia, v. 9 p. 66-72, 1994

COSTA, E. B. G; ALVES, J. J. A; SILVA, V. S. Um estudo da distribuição pluviométrica da microrregião do Seridó paraibano. In: I Workshop Internacional Sobre Água no Semiárido Brasileiro. Campina Grande $\mathrm{PB}, 2013$. 
DOS SANTOS, E. C. A. ARAÚJO; L. E. Marcelino, A. S. Análise climática da Bacia Hidrográfica do Rio Mamanguape. Revista brasileira de emgenharia agrícola e ambiental. v. 19, n. 1, p. 9-14, 2015.

ESPINOZA, E. S. Distúrbios nos ventos de leste no Atlântico tropical. 1996. 127f. Dissertação (Mestrado em Meteorologia) - Instituto Nacional de Pesquisas Espaciais, São José dos Campos, 1996.

FREITAS, A. C. V; FRANCHITO, S. H; RAO, V. B. Análise dos dados de precipitação provenientes de diferentes fontes, sobre a América do sul, com ênfase no Brasil. CLIMEP - Climatologia e Estudos da Paisagem, v. 5, p 5$18,2010$.

FREITAS, M. A. S. A Previsão de Secas e a Gestão Hidroenergética: O Caso da Bacia do Rio Parnaíba no Nordeste do Brasil. In: Seminário Internacional sobre Represas y Operación de Embalses, 2004, Puerto Iguazú. Anais do Seminário Internacional sobre Represas y Operación de Embalses. Puerto Iguazú: CACIER, v. 1. p. 1-1, 2004.

FREITAS, M. A. S. Um sistema de suporte à decisão para o monitoramento de secas meteorológicas em regiões semiáridas. Revista Tecnologia, v. 19, p. 8495, 2005.

IBGE - Instituto Brasileiro de Geografia e Estatística. Contagem da população 2010. Brasília: IBGE, 2010. S.P. Disponivel em: http://cidades.ibge.gov.br/xtras/home.php. Acesso em: 19 de Abril de 2015.

KOUSKY, V. E. Frontal influences on northeast Brazil. Monthly Weather Review, v. 107, n. 9, p. 1140-1153, 1979.

KOUSKY, V. E.; GAN, M. A. Upper tropospheric cyclones vórtices in the tropical south atlantic. Tellus, v. 33, p. 538-551, 1981.

MEDEIROS, E. R; BARROS, M. J. V; ROSA, P. R. O; Degradação da caatinga no Seridó Paraibano e as tendências ao processo de "desertificação". X simpósio brasileiro de geografia física aplicada. p. 1-9, 2003.

NASCIMENTO. S. S; ALVES. J. J. A; Caracterização geoambiental e suscetibilidade aos processos de desertificação no Seridó paraibano. In: XVI Encontro Nacional dos Geógrafos. 2010.

NUNES, L. H.; LOMBRADO, M. A. A questão da variabilidade climática. Uma reflexão crítica. Revista Instituto Geológico, São Paulo, 16(1/2), p. 21-31, 1995.

REPELLI, C. A.; FERREIRA, N. S.; ALVES, J. M. B.; NOBRE, C. A. (1998). Índice de anomalia de precipitação para o Estado do Ceará. In: Anais do X congresso brasileiro de meteorologia e VIII congresso da FLISMET, Brasília DF. Anais. 1998.

SANTOS, E. P.; CORREIA, M. F.; ARAGÃO, M. R. S.; SILVA, F. D. S. Eventos extremos de chuva e alterações no regime hidrológico da Bacia Hidrográfica do 
Rio São Francisco: Uma aplicação do índice RAI (Rainfall Anomaly Index). Engenharia Ambiental, v. 8, p. 315-330, 2011.

SANTOS, M. J. J; Caracterização e monitorização de secas. Instituto da Água - Direção de Serviços de Recursos Hídricos. 1998.

SILVA, A. L; SILVA, W. S; NASCIMENTO, M. B; SILVA, G. S; ARAÚJO, L. E. Avaliação da precipitação do município de João Pessoa-pb. Revista brasileira de agrotecnologia. $V_{7}$, n 3. P 123-136. 2017

SILVA, D. F.; SOUSA F. A. S.; KAYANO M. T.; GALVÍNCIO J. D. Influência da variabilidade climática global e de suas escalas temporais sobre a precipitação no Alto Mundaú (PE). Revista Brasileira de Geografia Física, v.2, p. 6482, 2009.

SILVA, G. S.; SILVA, W. S.; SILVA, A. L.; ALMEIDA, N. V.; ARAÚJO, L. E. Análise da Precipitação da Microrregião do Cariri Oriental Paraibano. Revista de Geociencias do Nordeste. V. 4, n. 1, 2018.

SORIANO, B. M. A. Caracterização climática de Corumbá-MS. Boletim de Pesquisa, 11. Corumbá: EMBRAPA-CPAP, 1997.

SOUZA, D. F; Balanço hídrico climatológico 1961-199o e índice de anomalia de chuvas (IAC) aplicado ao período de 2011, 2012 e 2013 para compreensão da seca de 2014 no município de Paranaíba/ms. In: X Fórum Ambiental da Alta Paulista, v. 10, n. 2, p. 471-482, 2014.

OLIVEIRA, E. M; PEREIRA, P. A. O dilema da semiaridez no Seridó paraibano: causas e consequências. In: II workshop internacional sobre água no semiárido brasileiro. 2015.

Uvo, C. R. B. A zona de convergência intertropical (ZCIT) e sua relação com na região norte e nordeste brasileiro. Dissertação de mestrado. INPE. São José dos Campos, 1989.

Recebido em $1^{\circ}$ de junho de 2020 Aceito 21 de julho de 2020 